\title{
Experimental Investigation of Dynamic Elastic Properties of Reinforced Coconut Shell Powder/Epoxy Resin Composites
}

\author{
AM Andezai ${ }^{1}$, LM Masu ${ }^{1}$ and M Maringa ${ }^{2}$ \\ ${ }^{1}$ Vaal University of Technology, Faculty of Engineering and Technology, Department of Mechanical Engineering, \\ Private Bag X021, Vanderbijlpark, Andries Potgieter Blvd, 1911, South Africa. \\ ${ }^{2}$ Central University of Technology, Faculty of Engineering and Technology, Department of Mechanical and Mechatronics \\ Engineering, Private Bag X20539, Bloemfontein, 9300, South Africa.
}

ORCID: 0000-0003-0154-8572 (Andekuba Andezai)

\begin{abstract}
The purpose of this study is to investigate experimentally the dynamic elastic behavior of a coconut shell powder filler reinforced epoxy resins composite of different filler sizes and volume fractions. The dynamic mechanical analysis of coconut shell powder reinforced epoxy composites was carried out with special reference to the effect of filler loading, and temperature. The result showed that the core properties of the components, morphology of the system and the nature of interface between the phases determine the dynamic mechanical properties of the composite. Below the glass transition temperature, the storage modulus was generally found to increase with increasing weight fraction of the reinforcing filler and a reverse trend as temperature rose through the glass transition temperature. The loss modulus was generally seen to decrease with decreasing filler weight fraction for temperatures below the glass transition point and vice versa. Moreover, the curves for loss modulus were seen to shift to lower temperatures with increasing filler content, signifying a decreasing glass transition temperature with increasing filler content. The damping factor was seen to decrease in magnitude with increasing content of filler, with a trend of the peak values shifting to the lower temperatures.
\end{abstract}

Keywords: Particle reinforcement; matrix, coconut shell powder; dynamic, loss and storage moduli; and damping factor

\section{INTRODUCTION}

Polymers are important for a range of applications due to their numerous attractive properties which include their light weight, ease of processing and affordability. Natural fibres are attractive as reinforcement for polymers due to their biodegradability, high stiffness and strength, and good ductility that combine with the good corrosion resistance and low coefficient of friction of polymers to increase their utility [1-7]. Fibre reinforced composites (FRCs) occur in the form of strong fibres, which are continuous or discontinuous and are bounded by a weaker matrix material. The work of this matrix is to protect the fibres and also to transmit the load to the fibres $[8,9]$.

The choice of composite materials as a replacement for metallic materials in fields such as the automobile industry has been on the increase; particularly as a result of the impressive weightsavings these materials offer [10]. Composite materials offer the advantages of low weight, resistance against fatigue, resistance to corrosion, ease to maintain, non-porous, and resistance to heat [11].They are less expensive when compared to other traditional materials like steel, aluminium, wood and granite [12,13].

Natural fillers and fibres reinforced thermoplastic composites have successfully proven their high qualities in various fields of technical application [14]. As replacements for conventional synthetic fibres like aramid and glass fibres, natural fibres are increasingly used for reinforcement of thermoplastics due to their low density, good thermal insulation and mechanical properties, reduced tool wear, unlimited availability, low prices, and problem free disposal [15]. The continuous demand for greater quantities of new materials with low density, low cost that are environmentally friendly, by different industries, has led to the study of new polymer composites containing easily available organic fillers. The mechanical, physical, and dynamic mechanical characterization of such composites is normally carried out to determine their suitability as new materials for different applications [16].

Wood fibres/particles provide a sufficient reinforcement at much lower cost than synthetic and mineral fillers. When synthetic and mineral fibres are used, machine wear and damage of processing equipment is much higher than with wood fillers [17]. Fibre damage during processing is greatly reduced when wood is utilized, which allows for recycling production waste without compromising quality [17].

Dynamic mechanical analysis (DMA) is a powerful technique that is used to investigate viscoelastic behaviour of polymers. The loaded specimens generally deform sinusoidally in response to an applied oscillating sinusoidal force. The resultant strain in specimens depends upon both their elastic and viscous behaviour. The storage modulus (or what is commonly referred to as elastic modulus) is a measure of the recoverable strain energy in a deformed specimen, and the loss modulus (or viscous modulus) is related to internal frictional losses which generate heat that is lost through dissipation. The damping factor defined as, Tan $(\delta)$, is equal to the ratio of loss to storage modulus and varies between $0^{\circ}$ and $90^{\circ}$. At $0^{\circ}$ the deformation of the material is all elastic, while at $90^{\circ}$ it is all 
viscous $[18,19,20,21]$. Several researchers have studied the effect of filler content on the dynamic mechanical behaviour of composites. The tensile modulus and tensile strength of the composites studied were found to increase with fibre content in accordance with the rule of mixtures [22, 23, 24]. Rajini et al [25] investigated the influence of nanoclay on woven coconut sheet/polyester composites dynamic mechanical properties and found that the addition of nanoclay increased the storage modulus and loss modulus of the composite materials. Several researchers have carried out studies on the mechanical and dynamic mechanical properties of natural fibre and particulate filler-reinforced polymers. The general conclusion arising from these studies is that reinforcing epoxy matrix with natural fibre or particulate fillers effectively improves the properties of the developed composite materials [15, 26, 27, 28, 29].

Green composites which consist of natural fibres and biodegradable resins are developed as substitutes to nonenvironmentally friendly materials like conventional plastics (petroleum derived polymers) and have the required strength values and stiffness for various applications. In the case of automobile components, fibres such as bamboo, hemp and kenaf which are light, strong, renewable, and inexpensive have been used in certain requirements instead of glass fibres [15]. Green composites are expected to be increasingly used in place of polymer composites made from fossil oil and in this way contribute to the maintenance of a sustainable productive society. Several green composites which consist of natural fibres as reinforcements and a biodegradable resin as a matrix material are proposed, such as coconut shell, flax, and jute [15]. Such composites are often desired for their advantages interalia light weight, low cost, high specific modulus, in addition to their abundant availability, simplicity of surface treatment, and biodegradability [17].

A particulate composite is composed of particles suspended in a matrix. The reinforcing particles may be spherical, cubic, tetragonal, platelet, or other shapes [30]. Generally, the reinforcing particles are very effective in improving the resistance of the matrix to fracture. These particles, however, only increase the stiffness of the matrix in the formed composite to a limited extent. Particle fillers are extensively used to enhance the properties of matrix materials including; modifying their thermal and electrical conductivities, increasing their performance at elevated temperatures, lowering their friction, increasing their wear and abrasion resistance, improving their machinability, increasing their surface hardness and reducing their shrinkage[31]. The mechanical properties of particulate-polymer composites depend strongly on the particle size, particle-matrix interface adhesion and particle loading. For example, smaller calcium carbonate particles provide higher strength of filled polypropylene composites at a given particle loading [32]. Smaller particle size yields higher fracture toughness for calcium carbonate filled high-density polyethylene (HDPE) [33]. Yang et al. [34, 35], studied the effect of maleate (ester of maleic acid) polypropylenes, compatibilizing agents on the mechanical properties and morphology of thermoplastic polymer composites filled with rice husk flour. The results obtained showed that as the filler loading increased, the composites made without any compatibilizing agent showed decreased tensile strength and more brittleness. The composites, however, exhibited significantly improved mechanical properties due to the incorporation of the compatibilizing agent. This behaviour was due to the poor interfacial binding existing between the filler and polymer matrix, which caused the composites to have low values of tensile strength, and improved interfacial binding and therefore improved tensile strength and modulus with the addition of maleated polypropylenes compatibilizing agent.

The aim of this research work was to investigate the dynamic elastic behavior of Coconut Shell Powder (CSP)/epoxy resin particulate composites as a function of filler size, and weight fraction.

\section{EXPERIMENTAL PROCEDURE}

\subsection{Materials}

The materials shown in Table 1 were used to prepare CSP/epoxy resin composites.

Table 1: Details of the resin system used in the present work

\begin{tabular}{|l|l|l|}
\hline \multicolumn{2}{|l|}{ Details of matrix, reinforcement, and release system } \\
\hline Matrix Details & Gurit \\
\hline Manufacturer & Epoxy \\
\hline Resin type & Prime 27 \\
\hline Resin Identification & Prime 27 slow hardener \\
\hline Matrix Hardener & 150 ųm CSP & 212 ųm CSP \\
\hline Product Name & \\
\hline Filler Details & Ram Wax & Ram Wax \\
\hline Filler material &
\end{tabular}

\subsection{Fabrication of the Composites}

The coconut shell was dried in the open air and ground into powder using a pulverizing machine, the powder was then sieved in accordance with BS 1377:1990 standard. The composite was fabricated using the method of hand lay-up. Firstly, the moulds for casting the test specimens were fabricated from glass with planer dimensions of $350 \times 550 \times 35$ $\mathrm{mm}$ and a thickness of $7.5 \mathrm{~mm}$. The mould was then coated with a transparent film of "ram-wax" on the inside to facilitate removal of the cast material from the mould upon cure. Coconut shell powder was then added into acetone in a glass jar and the mixture stirred at a low frequency of $10 \mathrm{~Hz}$ using a scientific ultra-sonic bath at a room temperature of $23^{\circ} \mathrm{C}$ for an hour in order to ensure an even distribution of the CSP in the acetone. The suspension was then added to epoxy resin in a jar, stirred and heated to a temperature of $140^{\circ} \mathrm{C}$ in order to evaporate the acetone thus leaving behind coconut shell powder 
dispersed in epoxy resin. The mixture was then placed in a scientific ultra-sonic bath and stirred till the mixture temperature cooled down to $21^{\circ} \mathrm{C}$. After this, hardener was added into the mixture of resin and coconut shell powder in the ratio of 3.57:1(100:28) resin: hardener as recommended by the supplier and stirred thoroughly for about 10 minutes to obtain a uniform mixture. The thoroughly stirred mixture was then placed in a vacuum chamber for degassing under a $-90 \mathrm{kPa}$ vacuum for 20 minutes to remove any entrapped air bubbles. The mixture was thereafter poured into the glass mould, sealed and allowed to cure for 8 hours. The cured composite was later post-cured in an oven for 8 hours at $65^{\circ} \mathrm{C}$. This whole process was repeated for the different weight percentages of $(5,10,15$, 20, 25 and 30) of the coconut shell particles. Thereafter, the specimens were cut to standard dimensions for each test to be carried out, using a CNC machine. The specimens were then exposed to dynamic testing in a Dynamic Mechanical Analysis (DMA) equipment in accordance with ASTM standards D638$02[36,37,38]$. Schematic drawings of the test specimens used with their dimensions are shown in Figure 1. Figure $2(\mathrm{a} \& \mathrm{~b})$ show the pouring of thoroughly mixed CSP and epoxy resin composite into a mould and cured composite inside an enclosed glass mould, respectively.

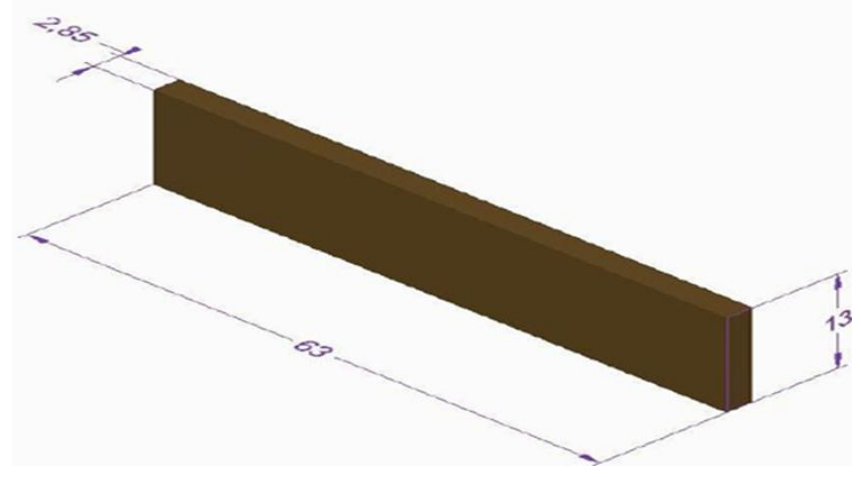

Figure 1: Schematic drawing Dynamic testing specimen according to ASTM: D5023-01

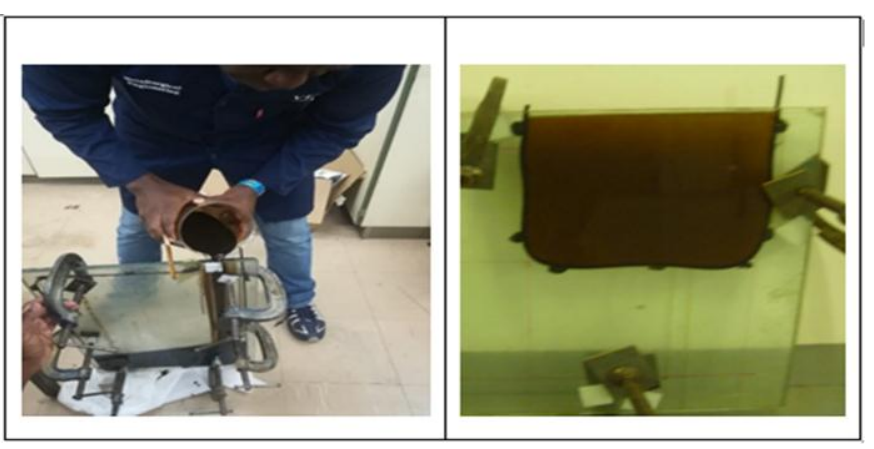

Figure 2: Pouring of the mixed reinforced coconut shell powder composite into a mould and a cast CSP epoxy resin/coconut particle composite

\subsubsection{Determination of Density}

The density of the CSP powder was determined using the method of displacement of water. A calibrated test tube with a known amount of water was placed on a Kern and Sohn electronic balance which has an accuracy of $\pm 0.1 \mathrm{mg}$. A known amount of coconut shell powder was then added into the test tube and the change in weight of the test tube and apparent volume of water in the test tube were noted. Rectangular pieces of pure epoxy resin and CSP/epoxy resin composites were cut out from the cast plates and their dimensions measured using a vernier calliper. A set of three specimens was used to determine the density of composites for each type of composite and for the epoxy resin too. Their weights were determined on the Kern and Sohn electronic balance and their density calculated using the formula shown in Equation (1):

$$
\text { Density }=\frac{\operatorname{Mass}(\mathrm{g})}{(\text { apparent volume-original Volume })\left(\mathrm{cm}^{3}\right)}
$$

\subsection{Dynamic Mechanical Testing}

The specimens were tested as double-cantilevers using a TAInstruments DMA Q800 test machine that has both flexural and cantilever jigs with a preload of $0.01 \mathrm{~N}$. The double cantilever method was adopted due to the ease of manufacturing specimens and amenability to simple standardised analysis, in addition to the ability to measure small deflections, compared to the single cantilever. The TA-Instruments DMA Q800 has a strain resolution of $1 \mathrm{~nm}$, with the ability to run tests in a controlled test atmosphere, with a maximum amplitude of dynamic vibrations of $15 \mu \mathrm{ms}$, and force track of $125 \%$ (reduces the static force as the sample softens to minimize the risk of creep during the test). A frequency of $1 \mathrm{~Hz}$ and temperature range of $20^{\circ} \mathrm{C}-140^{\circ} \mathrm{C}$ were set in this test. A schematic drawing of a double cantilever with dimensions is shown in Figure 3.

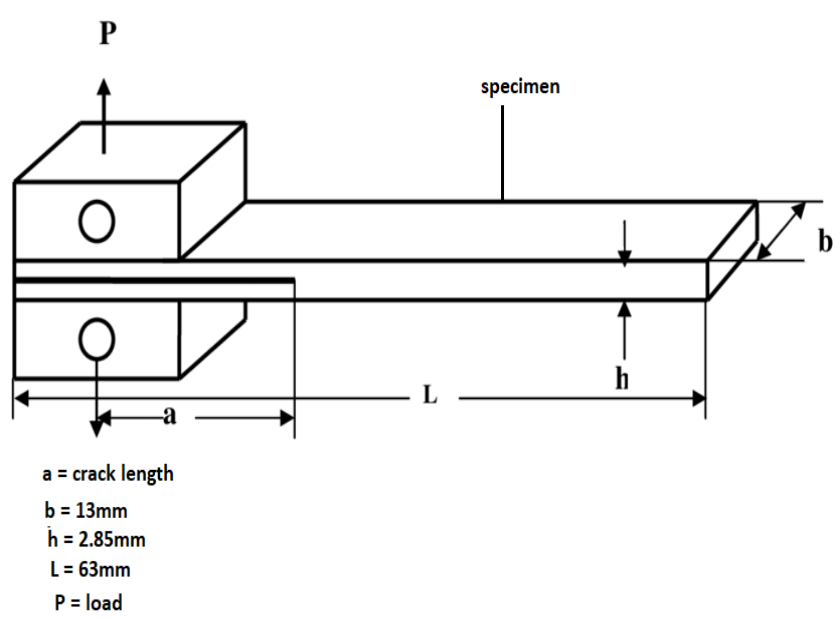

Figure 3: Schematic drawing of a double cantilever with dimensions

\section{RESULTS AND DISCUSSION}

The results of density, and dynamic mechanical analysis of CSP/epoxy resin composites with different weight percentages of the CSP filler are now presented together with accompanying discussions. 


\subsection{Density of CSP and CSP/Epoxy Resin Composites}

The approximate value of the density of CSP was determined to be $1.60 \mathrm{~g} / \mathrm{cm}^{3}$. Table 2 shows the values of density that were determined experimentally for epoxy resin, as well as CSP/epoxy resin composites with CSP particles of $150 \mu \mathrm{m}$ and $212 \mu \mathrm{m}$, for different weight fractions of CSP.

Figure 4 shows the experimental values of density of epoxy resin and CSP/epoxy resin reinforced composites for different weight percentages of CSP filler.

Table 2: Experimental values of the density of epoxy resin and CSP/epoxy resin composites

\begin{tabular}{|c|c|c|}
\hline $\begin{array}{c}\text { Weight percentage of } \\
\text { filler }\end{array}$ & $\begin{array}{c}\text { Average density of } \mathbf{1 5 0} \boldsymbol{\mu m} \\
\text { CSP composite }\left(\mathbf{g} / \mathbf{c m}^{\mathbf{3}}\right)\end{array}$ & $\begin{array}{c}\text { Average density of } \mathbf{2 1 2} \boldsymbol{\mu m} \\
\text { CSP composite }\left(\mathbf{g} / \mathbf{c m}^{\mathbf{3}}\right)\end{array}$ \\
\hline Pure epoxy resin & $1.18 \pm 0.06$ & $1.18 \pm 0.06$ \\
\hline $5 \%$ & $1.12 \pm 0.01$ & $1.16 \pm 0.03$ \\
\hline $10 \%$ & $1.18 \pm 0.06$ & $1.10 \pm 0.14$ \\
\hline $15 \%$ & $1.22 \pm 0.03$ & $1.15 \pm 0.04$ \\
\hline $20 \%$ & $1.22 \pm 0.03$ & $1.16 \pm 0.03$ \\
\hline $25 \%$ & $1.22 \pm 0.03$ & $1.21 \pm 0.04$ \\
\hline $30 \%$ & $1.22 \pm 0.03$ & $1.23 \pm 0.03$ \\
\hline
\end{tabular}

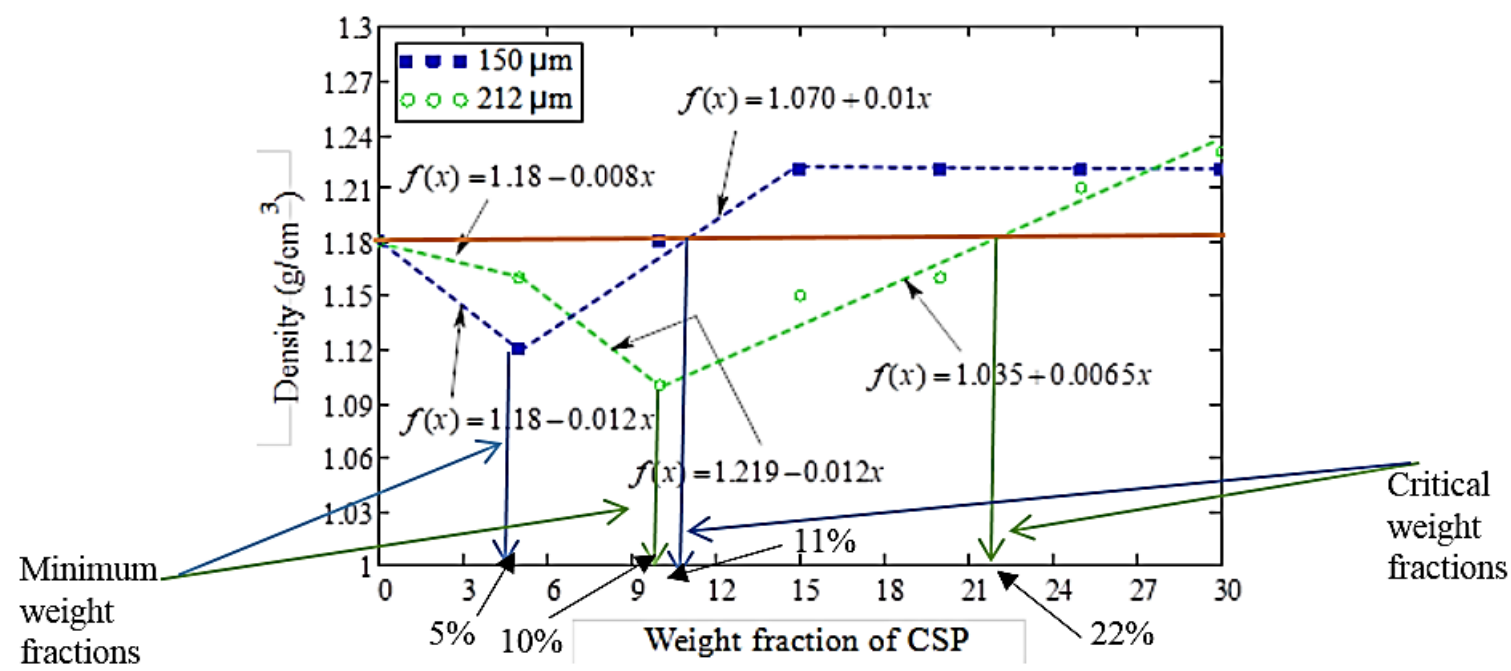

Figure 4: Experimental values of density of epoxy resin and CSP/epoxy resin reinforced composites for different weight percentages of CSP filler.

Figure 4 shows the density of the neat epoxy matrix to be $1.18 \mathrm{~g} / \mathrm{cm}^{3}$. Both curves in Figure 4 exhibited an initial decrease of density till weight fractions of $5 \mathrm{wt} \%$ for the $150 \mu \mathrm{m} \mathrm{CSP}$ particle/epoxy resin composites and $10 \mathrm{wt} \%$ for the $212 \mu \mathrm{m}$ CSP particle/epoxy resin composites. Points of critical weight fraction for the two composites of $11 \mathrm{wt} \%$ for the $150 \mu \mathrm{m}$ CSP particle/particle composites and $22 \mathrm{wt} \%$ in the case of $212 \mu \mathrm{m}$ CSP particle/particle composites are also evident in the figure. Beyond the minimum weight fraction, there was a monotonic increase of density between weight fractions of $5-16 \%$ for the $150 \mu \mathrm{m}$ CSP particle/epoxy resin composite after which the curve more or less levelled out horizontally denoting saturation of reinforcement. For the $212 \mu \mathrm{m}$ CSP particles/epoxy resin composite there was a linear increase till a weight fraction of about $28 \%$, at which point the density dipped. The minimum and critical weight fractions are normally evident in fibre reinforced composites and not in a particulate composite as is seen here, the latter whose variations of mechanical properties rather conform to the Reuss rule. Below the minimum weight fraction the particles weaken the material rather than strengthen it, as the reinforcing is only effective when the particle weight fraction exceeds the critical weight fraction. The experimental results in this work show a similar trend to the results presented by Obiukwu et al $[39,40]$.

\subsection{DYNAMIC MECHANICAL ANALYSIS}

Figure 5 ( $a \& b$ ) show the variation of the storage modulus with temperature for pure epoxy resin and different coconut shell 
powder composite volume fractions of $150 \mu \mathrm{m}$ and $212 \mu \mathrm{m}$

CSP/epoxy resin composites.

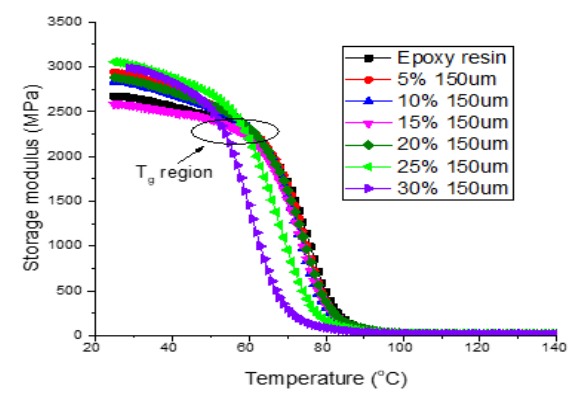

(a) $\quad 150 \mu \mathrm{m} \mathrm{CSP/epoxy} \mathrm{resin} \mathrm{composites}$

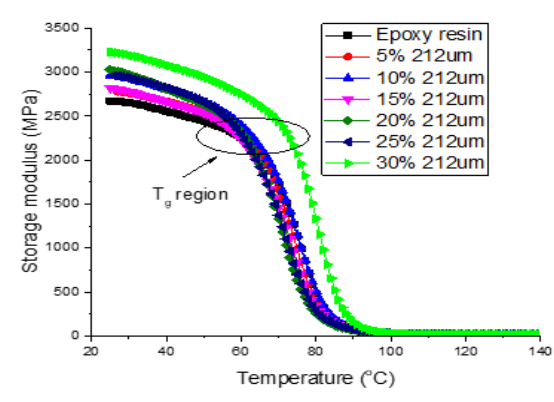

(b) $\quad 212 \mu \mathrm{m} \mathrm{CSP/epoxy} \mathrm{resin} \mathrm{composites}$

Figure 5: Variation of the storage modulus (E') with temperature for pure epoxy resin and CSP/epoxy resin composites reinforced with different weight fractions of CSP of $150 \mu \mathrm{m}$ and $212 \mu \mathrm{m}$ average particle sizes.

The curves for both the $150 \mu \mathrm{m}$ and $212 \mu \mathrm{m}$ CSP/epoxy resin composites shown in Figure 5 reveal that addition of coconut shell powder particles leads to a general increase and decrease in the magnitude of storage modulus to the left and right of the glass transition temperature, respectively, with increasing weight fraction of the reinforcing CSP filler. These trends are more significant for the $150 \mu \mathrm{m}$ CSP/epoxy resin composites than for the $212 \mu \mathrm{m} \mathrm{CSP/epoxy} \mathrm{resin} \mathrm{composites.} \mathrm{Thus,} \mathrm{for}$ instance, at $25^{\circ} \mathrm{C}$, the storage modulus for pure epoxy resin is equal to $2.673 \mathrm{GPa}$ and at $70^{\circ} \mathrm{C}$ it is $1.713 \mathrm{GPa}$. While at $25^{\circ} \mathrm{C}$ and $70^{\circ} \mathrm{C}$ for both $212 \mu \mathrm{m} \mathrm{CSP/epoxy} \mathrm{resin} \mathrm{composites} \mathrm{and} 150$ $\mu \mathrm{m}$ CSP/epoxy resin composites, the respective values are 3.040 $\mathrm{GPa}$ and $1.328 \mathrm{GPa}$, and $2.879 \mathrm{GPa}$ and $1.622 \mathrm{GPa}$, respectively. The higher values of storage modulus for the 150 $\mu \mathrm{m}$ filler particles is suggested to be as a result of increased reinforcing effect the smaller filler particles, which is consistent with the work of Haghtalab A and Marzban R [41].

Figure $6(\mathrm{a} \& \mathrm{~b})$ depict the variation of the loss modulus with temperature for the different CSP/epoxy resin composites of $150 \mu \mathrm{m}$ and $212 \mu \mathrm{m}$ CSP filler sizes.

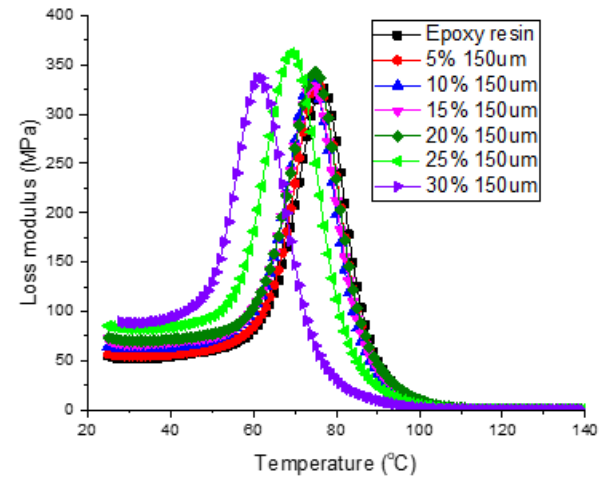

(a) $150 \mu \mathrm{m}$ CSP/epoxy resin composites

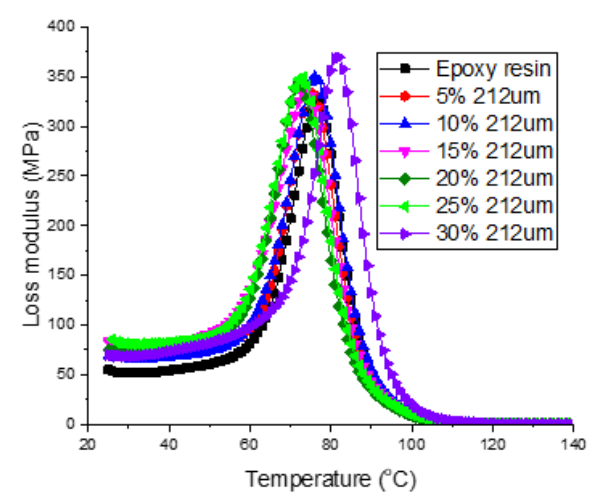

(b) $\quad 212 \mu \mathrm{m} \mathrm{CSP/epoxy} \mathrm{resin} \mathrm{composites}$

Figure 6: Variation of the loss modulus (E") with temperature for the pure epoxy resin and CSP/epoxy resin composites reinforced with different weight fractions of CSP with $150 \mu \mathrm{m}$ and $212 \mu \mathrm{m}$ particles sizes.

The graphs for the loss modulus in Figure 6 show curves with different amplitudes. To the left and right of the glass transition temperature, the loss modulus is seen to generally increase and decrease, respectively, with increasing weight fraction of the reinforcing filler. The curves in Figure 6 also show a shift to the left with increasing weight fraction of the filler particles. This is because of restrictions imposed on the mobility of the polymer molecules at the interface. The $\alpha$-relaxation (glass transition temperature) suggests a more complex structural relaxation behaviour by the composites. These trends are consistent with observation of decreases in the mobility of the matrix thus leading to an increase of the loss modulus at any temperature to the left of the transition temperature, and peaks at lower temperatures with increasing filler content. This is primarily attributed to the segmental immobilization of the matrix chain at the filler surface [41]. 
Figure 7 (a \& b) present the variation of the damping ratio for CSP/epoxy resin composites of different weight fractions for $150 \mu \mathrm{m}$ and $212 \mu \mathrm{m}$ CSP particle sizes.

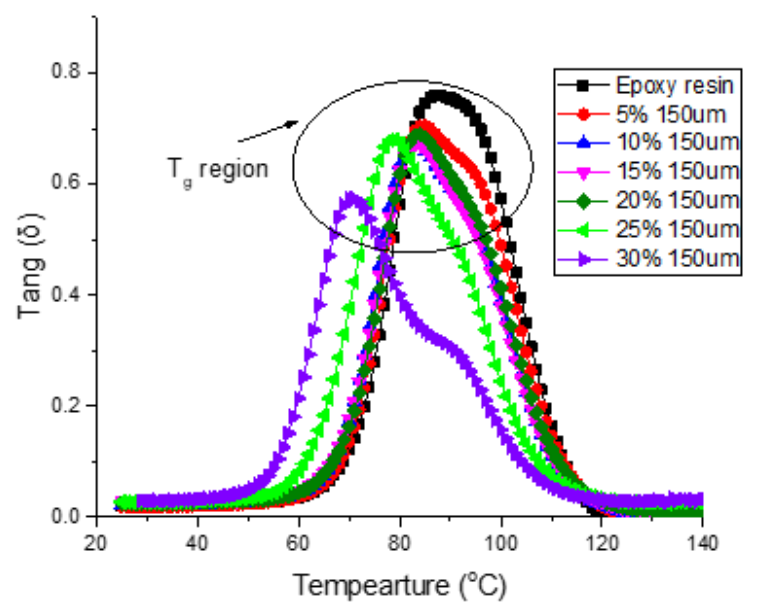

(a)

$150 \mu \mathrm{m}$ CSP/epoxy resin composites

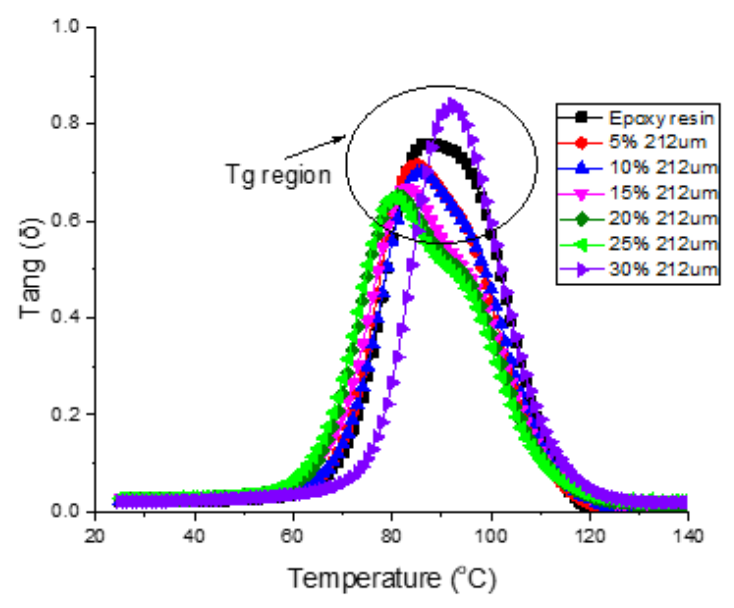

(b) $\quad 212 \mu \mathrm{m} \mathrm{CSP/epoxy} \mathrm{resin} \mathrm{composites}$

Figure 7: Damping curves for CSP/epoxy resin composites of coconut shell powder of $150 \mu \mathrm{m}$ and $212 \mu \mathrm{m}$ average sizes.

In Figure 7 the curves reveal a reduction in the damping capacity and a shift to the left of the glass transition temperature of CSP/epoxy resin composites with increasing weight fraction of the reinforcing filler. Outside this temperature range the damping factor is lower. To the left and right of the glass transition temperature, the damping factor increases and decreases generally with increasing weight fraction of the reinforcing filler, respectively. The decreasing magnitudes of the peaks, as well as reduction of the glass transition temperature with increasing weight fraction of the reinforcing filler is indicative of increasing stiffness of the composites with increasing reinforcement.

\subsection{CONCLUSIONS}

The following conclusions can be drawn from this work:

1) The density of CSP/epoxy resin composites exhibited the standard variations with weight fraction that are common to reinforced composites, complete with minimum and critical weight fractions.

2) Coconut shell powder increased the capacity of epoxy resin matrix to support mechanical loads below the glass transition temperature for both filler particles sizes, with a similar and converse trend above this temperature for the $212 \mu \mathrm{m}$ and $150 \mu \mathrm{m}$ particle size composites, respectively, as evidence by the trends of the curves for storage modulus.

3) The structural damping effect of the composites was higher for higher filler contents for both particle size composites below the glass transition temperature, and the converse and similar trend above this temperature for the $150 \mu \mathrm{m}$ ad $212 \mu \mathrm{m}$ filler particle composites, respectively.
4) That the damping peaks were generally lowered by an increase in filler content, while shifting to low glass transition temperatures as well is indicative of increased damping effect as a function of reinforcement.

\section{CONFLICT OF INTEREST}

The researchers have no conflict of interest to disclose with regard to the current research work.

\section{ACKNOWLEDGEMENT}

This research work was supported by the Vaal University of Technology (VUT), South Africa and Council for Scientific and Industrial Research (CSIR), South Africa.

\section{REFERENCES}

[1] Daniel, I, M., and Ishai, O., 2006, Engineering mechanics of composite materials, 2nd edn. ISBN 9780-19-515097-1.

[2] Thakur, V.K., Thakur, M.K., and Gupta, R.K., 2014, "Raw natural fibre-based polymer composites". International Journal of Polymer Analysis and Characterization.19(3), pp. 256-271.

[3] Ku. H., Wang, H., Pattarachaiyakoop, N., and Trada, M., 2011, "A review on the tensile properties of natural fibre reinforced polymer composites". Composites Part B: Engineering. 42(4), pp. 856-873.

[4] Barari, B., Ellingham, T.K., Ghamhia, Ii, Pillai, K.M, ElHajjar, R., and Turng. Ls, Et Al., 2016, "Mechanical characterization of scalable cellulose nano-fibre based 
composites made using liquid composite moulding process". Composites Part B: Engineering. (84), pp. 277284.

[5] Unterweger, C., Brüggemann, O., and Fürst, C., 2014, "Synthetic fibres and thermoplastic short-fibre reinforced polymers: Properties and characterization". Polymer Composites. 35(2), pp. 227-236.

[6] Santos, T.F.A., Vasconcelos, G.C., De Souza, W.A., Costa. M.L., and Botelho, E.C., 2015, "Suitability of carbon fibre-reinforced polymers as power cable cores: Galvanic corrosion and thermal stability evaluation". Materials \& Design (1980- 2015). (65), pp. 780-788.

[7] Pei, X.Q., Bennewitz, R., and Schlarb, A.K. 2015," Mechanisms of friction and wear reduction by carbon fibre reinforcement of PEEK. Tribology Letters". 58(3), pp. 42.

[8] Broza, G., and Schulte, K., 2008, "Melt processing and filler/matrix interphase in carbon nanotube reinforced poly (ether-ester) thermoplastic elastomer". Polymer Engineering Science, 48(10), pp. 2033-8.

[9] Jauhari, N., Mishra, R., and Thakuri, H., 2015, "Natural fibre reinforced composite laminates". A Review. Materials Today: Proceedings, Vol. 2, pp. 2868-2877.

[10] Pervaiz, M., Panthapulakkal, S., Birat, K.C, Sain, M., and Tjong, J., 2016, "Emerging trends in automotive light weighting through novel composite materials". Material Science and Application, Vol. 7, pp. 26-38.

[11] Chandramohan, D., and Marimuthu, K., 2011, “A review on natural fibres". IJRRAS, 8(2), pp. 194-206.

[12] Rao, M.D., 2003, "Recent applications of viscoelastic damping for noise control in automobiles and commercial airplanes". Journal of Sound and Vibration, 262(3), pp. 457-74.

[13] Neitzel, I., Mochalin, V., Koki, I., Palmese, G.R., and Gogotsi, Y., 2011, "Mechanical properties of epoxy composites with high contents of nanodiamond". Composite Science Technology, 71(5), pp. 710-6.

[14] Abass, R.U, Abass, F.U., and Abas, M.O., 2015, "Improvement of Mechanical Properties of Polyester Composite Reinforced By Bio Filler (Acro Shell)". International Journal of Innovative Science, Engineering \& Technology, 2(3)

[15] Mohammed, L., Ansari, M.N.M., Pua, G., Jawaid, M., and Saiful Islam, M., 2015, "A review of natural fibre reinforced polymer". Composite and Its Application. International Journal of Polymer Science.1-15.

[16] Kinoshita, H., Kaizu, K., Fukuda, M., Tokunaga, H., Keisuke Koga, K., and Ikeda, K., 2009, "Development of green composite consists of woodchips, bamboo fibres and biodegradable adhesive". Composite Part B: Engineering, Vol. 40, pp. 607-612.

[17] Seth, S. A., Aji, I. S., and Tokan, A., 2018, "Effects of Particle Size and Loading on Tensile and Flexural Properties of Polypropylene Reinforced Doum Palm Shell Particles". Composites American Scientific Research Journal for Engineering, Technology, and Sciences, 44(1), pp. 231-239.
[18] Bhaskar, J., and Singh, V.K., 2013, "Physical and mechanical properties of coconut shell particle reinforced-epoxy composite". Journal of Material and Environmental Science. 4 (2), pp. 227-232.

[19] Ojha, S., Gujjala, R., and Acharya, S. K., 2014, "Effect of filler loading on mechanical and tribological properties of wood apple shell reinforced epoxy composite". Advances in Materials Science and Engineering, doi.org/10.1155/2014/538651.

[20] Idicula, M., Malhotra, S.K., Joseph, K., and Thomas, S., 2005, "Dynamic mechanical analysis of randomly oriented intimately mixed short banana/sisal hybrid fibre reinforced polyester composites", Compos. Sci. Technol. Vol. 65, pp. 1077-1087.

[21] D. Ray, D., Sarkar, B.K., Das, S., and Rana, A.K., 2002, "Dynamic mechanical and thermal analysis of vinyl ester-resin-matrix composites reinforced with untreated and alkali-treated jute fibres", Compos. Sci. Technol. Vol. 62, pp. 911-917.

[22] A. K. Saha, A.K., Das, S., Bhatta, D., and Mitra, B.C., 1999, "Study of Jute Fibre Reinforced Polyester Composites by Dynamic Mechanical Analysis," J. Appl. Polym. Sci., Vol. 71, pp. 1505-1513.

[23] Pashaei, S., Siddaramaiah, S., and Syed, A. A., 2011, "Thermal characteristics of nanostructured fillerincorporated polyvinyl ester nanocomposites". Polym. Plast. Technol. Eng. 50(10), pp. 973-982.

[24] Ashok, B., Reddy, S. K. O., Madhukar, K., Cai, J., Zhang, L., and Rajulu, A. V., 2014, "Tensile and thermal properties of poly (lactic acid)/eggshell powder composite films". Int. J. Polym. Anal. Charact. 19(3), pp. 245-255.

[25] Yasmin, A., and Daniel, I. M., 2004, "Mechanical and thermal properties of graphite platelet/epoxy composites". Polymer 45(24), pp. 8211-8219.

[26] Rajini, N., J. T. Winowlin Jappes, and Jeyaraj, P., 2013, "Effect of montmorillonite nanoclay on temperature dependence mechanical properties of naturally woven coconut sheath/polyester composite". J. Reinf. Plast. Compos. 32 (11), pp. 811-822.

[27] Fu, S.Y., Feng, X.Q., Lauke, B. and Mai, Y.W., 2008, "Effects of particle size, particle/matrix interface adhesion and particle loading on mechanical properties of particulate-polymer composites". Composites Part B: Engineering, 39(6), pp.933-961.

[28] Saba, N., Paridah, M.T. and Jawaid, M., 2015, "Mechanical properties of kenaf fibre reinforced polymer composite": A review. Construction and Building materials, 76, pp.87-96.

[29] Alshammari, B.A., Saba, N., Alotaibi, M.D., Alotibi, M.F., Jawaid, M. and Alothman, O.Y., 2019, "Evaluation of mechanical, physical, and morphological properties of epoxy composites reinforced with different date palm fillers". Materials, 12(13), pp.2145.

[30] Alshammari, B.A, Saba, N., Alotaibi, M.D., Alotibi, M.F., Jawaid, M., and Alothman, O.Y., 2019, "Evaluation of mechanical, physical, and morphological 
properties of epoxy composites reinforced with different date palm fillers". Materials (Basel). 12(13), pp. 2145.

[31] Verma, D., Cope, P.C., Shandilya, A., Gupta, A., and Maheshwari M.K., 2013, "Coir fibre reinforcement and application in polymer composite": A review. Journal of Material Environment Science, 4(2), pp. 263-276.

[32] Lau, K.T., Gu, C., and Hui, D., 2006, “A critical review on nanotube and nanotube/ nanoclay related polymer composite materials". Composites Part B, Vol.37, pp. 425-36.

[33] Bartczak, Z., Argon, A.S., Cohen, R.E., and Weinberg, M., 1999, "Toughness mechanism in semi-crystalline polymer blends: II. High-density polyethylene toughened with calcium carbonate filler particles". Polymer, Vol.40, pp. 2347-65.

[34] Yang, H.S., Kim, H.J., Park, H.J., Lee, B.J. and Hwang, T.S., 2007, "Effect of compatibilizing agents on ricehusk flour reinforced polypropylene composites". Composite Structures, 77(1), pp. 45-55.

[35] Yang, H.S., Kim, H.J., Son, J., Park, H.J., Lee, B.J. and Hwang, T.S., 2004, "Rice-husk flour filled polypropylene composites, mechanical and morphological study". Composite structures, 63(3-4), pp. 305-312.

[36] Standard Test Method for Unnotched Cantilever Beam Impact Resistance of Plastics, Designation: D 4812 - 99, Annual Book of ASTM Standard, Volume 08.02 Plastics (II): D 3222 - D 5083, 2007.

[37] Standard Test Method for Plastics: Dynamic Mechanical Properties: In Flexure (Three Point Bending), Designation: Annual Book of ASTM Standard, D 5023 - 01, Annual Book of ASTM Standard, Volume 08.02 Plastics (I): D256-D 3159(2001).

[38] Standard Test Method for Plastics: Dynamic Mechanical Properties: In Flexure (Dual Cantilever Beam), Designation: Annual Book of ASTM Standard, D 5418 - 01, Annual Book of ASTM Standard, Volume 08.03 Plastics (I): D256-D 3159(2001).

[39] Obiukwu, O.O., Uchechukwu, M. N., and Nwaogwugwu, M. C., 2016, "Study on the properties of coconut shell powder reinforced high-density polyethylene composite", Futo Journal Series.2 (2), pp. 43-55.

[40] Vinay K.S., 2014, "Mechanical behavior of walnut shell particles reinforced bio-composite". Sci Eng Compos Mater

[41] Haghtalab, A., and Marzban, R., 2011, "Properties of nanosilica-filled polypropylene in the molten state: Effect of particle size". Advances in Polymer Technology, 30(3), pp. 202-218. 